JURNAL MAKSIPRENEUR, Vol. VI, No. 2, Juni 2017, hal. 1 - 17

\title{
PENGARUH EMPLOYEE ENGAGEMENT TERHADAP KINERJA KARYAWAN PROGRAM DIPLOMA III DI FAKULTAS EKONOMI UNIVERSITAS ISLAM INDONESIA
}

\author{
Rizqi Adhyka Kusumawati \\ Program Diploma III Ekonomi Universitas Islam Indonesia Yogyakarta \\ Korespondensi penulis: adhyka.taufan@gmail.com
}

\begin{abstract}
This research aims to study the independent variable (employee engagement) that affects employee performance in a positive and significant way. The questionnaire used in this research is a questionnaire that has been adapted to the theory of analysis used. The overall statement in the questionnaire is a favorable statement with 13 respondents who are all employees of D-3 Program in Faculty of Economics of Islamic University of Indonesia (UII). The results of multiple linear regression analysis show that employee engagement variable influence employee performance with a positive, but not significant way. It can be seen from the results of the F-test that shows $F_{\text {count }}<F_{\text {tabel }}$ $(6.15<8.81)$ and shown by the value of coefficient of determination $\left(R^{2}\right)$ of 0.969 . The result of t-test gives all factors in employee engagement variable does not affect employee performance variable and collaborate factor is not dominant factor influence employee performance, whereas convey factor has the biggest influence to employee performance according to coefficient value.
\end{abstract}

Keywords: human resource, employee engagement, employee performance

\section{PENDAHULUAN}

Seorang karyawan dalam suatu perusahaan dapat dikatakan memiliki kinerja yang baik apabila karyawan tersebut memiliki keterikatan yang erat dengan perusahaannya yang membuat karyawan tersebut (tanpa keterpaksaan) mau memberikan kontribusi yang optimal bagi perusahaannya. Namun karyawan yang telah cukup lama bekerja di perusahaan pun, pada suatu ketika dapat berada di posisi pada penurunan kontribusinya kepada perusahaan. Ketidakoptimalan kontribusi manusia sebagai karyawan dapat disebabkan oleh dua faktor yaitu faktor internal berasal dari dalam diri karyawan dan faktor eksternal berasal dari organisasi (Suparyadi, 2015: 299). Faktor internal yang mempengaruhi kinerja yang tidak optimal adalah cipta, rasa, karsa yang dimiliki oleh masing-masing karyawan. Sedangkan faktor eksternal yang menyebabkan ketidakoptimalan kinerja karyawan adalah lingkungan kerja seperti hubungan dan dukungan dari pemimpin dan rekan kerja, dukungan peralatan kerja, dan lain-lain (Suparyadi, 2015: 299).

Pada dasarnya, para pemimpin sudah pasti melakukan hal-hal yang diyakini dapat membuat karyawan-karyawannya melakukan apa yang diinginkan pemimpin tersebut. Namun tidaklah mudah menanamkan suatu hal positif ke dalam benak seorang individu 
karyawan, sehingga pada kenyataannya seorang pemimpin harus dapat menjangkau bagian tersulit dari seorang karyawan, agar karyawan tersebut dapat menerima dengan jelas apa yang diinginkan pemimpinnya. Beberapa hal sederhana yang dilakukan oleh para pemimpin adalah memberikan petunjuk (direction), rasa hormat (respect), memberitahukan (inform), Nilai-nilai (values), energi (energy), model peran (role model). Namun, kepemimpinan yang hebat sekali pun dengan kemampuan tersebut tidaklah cukup hanya untuk membawa perusahaan dengan kinerja unggul. Faktor yang paling krusial dan senantiasa harus dijaga oleh perusahaan adalah karyawan dengan keterikatan yang tinggi terhadap perusahaannya. Pada akhirnya, seringkali muncul pertanyaan mendasar seperti apa yang sebenarnya dilakukan oleh para pemimpin besar bagi perusahaannya? Apakah seluruh karyawan telah memiliki engagement yang tinggi terhadap perusahaan?

\section{TINJAUAN PUSTAKA}

\section{Employee Engagement}

Secara detail dan sederhana, James Heskett dan beberapa kawannya di Havard Business School tahun 1994, mempublikasikan seminar paper mereka yang berjudul "Putting The Service - Profit Chain To Work" (yang dikenal dengan The ServiceProfit Chain Model) dan mengungkapkan bahwa seorang individu karyawan yang puas terhadap pekerjaan dan perusahaannya secara otomatis akan (dengan rela dan senang hati) terikat dengan perusahaannya. Karyawan yang puas juga akan mempunyai rasa memiliki yang besar terhadap perusahaannya yang selanjutnya akan menghasilkan produktivitas yang tinggi. Produktivitas tersebut akan mempengaruhi nilai-nilai dalam memberikan jasa layanan kepada pelanggan yang selanjutnya akan menghasilkan kepuasan pelanggan. Pelanggan yang puas akan menjadi loyal dan pada akhirnya akan membawa dampak terhadap peningkatan profit dan pertumbuhan perusahaan.

Towers Perrin Model menyimpulkan bahwa karyawan yang terikat dengan perusahaan adalah karyawan yang memiliki respon positif atas aspek Think, Feel, dan Act. Think merupakan kepercayaan dan dukungan untuk tujuan-tujuan atau nilainilai dalam suatu perusahaan; Feel merupakan rasa memiliki, rasa bangga, dan rasa keterikatan (ketertarikan yang tinggi) dengan perusahaan; dan Act merupakan kemauan untuk maju lebih jauh; memiliki keinginan untuk tinggal dalam perusahaan. Ketiga aspek tersebut akan membawa dampak pada perusahaan berupa munculnya potensi kepuasan pelanggan yang tinggi dan pada akhirnya akan menghasilkan kinerja bisnis yang positif dan signifikan.

Penelitian terkait dengan Employee Engagement telah dilakukan oleh Crim dan Seijts (2006) dan menyimpulkan bahwa terdapat 10 faktor yang mempengaruhi keterikatan karyawan (Employee Engagement) terhadap perusahaan. Salah satu faktor yang paling krusial adalah keterkaitan antara employee engagement dengan kepemimpinan. Sehubungan dengan hal tersebut, para pemimpin dapat menyatukan apa yang ada di kepala dan hati karyawan-karyawannya dengan menerapkan 10C dari Employee Engagement, yaitu: 1) Connect, 2) Career, 3) Clarity, 4) Convey, 5) Congratulate, 6) Contribute, 7) Control, 8) Collaborate, 9) Credibility, dan 10) Confidence.

Oleh karena itu, salah satu upaya Universitas Islam Indonesia (UII) dalam meningkatkan kinerja perusahaan adalah dengan senantiasa melakukan perbaikan 
yang meliputi segala aspek dalam organisasi terutama aspek sumber daya manusia yaitu meningkatkan kinerja karyawan.

\section{Kinerja Karyawan}

Sebuah organisasi dikatakan dapat membangun keunggulan bersaing ketika perusahaan tersebut dapat memberdayakan sumber daya manusianya secara optimal dalam rangka pencapaian tujuan perusahaan. Perusahaan seperti ini, hanya memiliki pilihan untuk menerapkan sistem manajemen kinerja di mana kualitas individu atau hasil yang dicapai, secara fundamental ditentukan oleh keahlian dan kemampuan individu yang bersangkutan (Alwi, 2008).

Menurut Simamora (2004) maksud penetapan tujuan kinerja adalah menyusun sasaran yang berguna tidak hanya bagi evaluasi kinerja pada akhir periode telaah, tetapi juga untuk mengelola proses kerja selama periode tersebut. Ada tidaknya alasan mengapa penentuan sasaran mempengaruhi kinerja antara lain: a) Penentuan sasaran mempunyai dampak mengarahkan yaitu memfokuskan aktivitas ke arah tertentu dari pada lainnya, b) Sasaran yang telah diterima maka orang cenderung mengerahkan upaya secara proposional terhadap kesulitan dan c) Sasaran yang sukar akan membuahkan kekuatan dibandingkan sasaran yang ringan.

Untuk mengukur kinerja, terlebih dahulu harus ditetapkan kriterianya. Menurut Bernardin (2010) terdapat enam kriteria untuk menilai kinerja karyawan, yaitu quality, quantity, timeliness, cost effectiveness, need for supervision, dan interpersonal impact. Meskipun semua kriteria tersebut mungkin tidak relevan dengan setiap aktivitas pekerjaan atau fungsi pekerjaan, namun sebuah subset dari kriteria tersebut dapat terjadi sehingga penting bagi perusahaan untuk mengenali hubungan antar kriteria. Karena penilaian kinerja yang efektif berfokus pada catatan hasil dan sebagian hasil secara langsung berhubungan dengan tujuan dan misi perusahaan.

\section{PENELITIAN YANG RELEVAN}

Penelitian tentang Employee Engagement telah dilakukan sejak tahun 1990 hingga saat ini. Kahn adalah peneliti pertama yang mengawali penelitian tentang Employee Engagement pada tahun tersebut. Kahn pada waktu itu melakukan studi etnografik dari keterikatan dan ketidakterikatan pribadi individu yang hasilnya telah dipublikasi 24 tahun yang lalu (Saks \& Gruman, 2014: 156). Kahn mendefinisikan employee engagement sebagai pemberdayaan atau pemanfaatan diri anggota organisasi untuk peran pekerjaan mereka, dalam keterlibatan, seorang individu dalam organisasi mempekerjakan dan mengekspresikan diri secara fisik, kognitif, dan emosional selama bekerja.

Kemudian, May et al (2004) menemukan bahwa kebermaknaan, keselamatan, dan ketersediaan berhubungan secara signifikan dengan engagement. Mereka juga menemukan bahwa pengayaan pekerjaan (job enrichment) dan peran, cocok menjadi prediktor positif dari kebermaknaan, menguntungkan hubungan rekan kerja, dan mendukung pengawas adalah prediktor positif keselamatan, sedangkan kepatuhan terhadap norma antarsesama rekan kerja dan kesadaran diri adalah prediktor yang negatif (Kular, Rees, \& Truss, 2008: 5).

Pada tahun-tahun berikutnya, penelitian tentang employee engagement tetap dilakukan dan dilanjutkan oleh beberapa ahli, salah satu di antaranya adalah Dan Crim dan Gerard Seijts yang melakukan penelitian tahun 2006 dan menyimpulkan bahwa terdapat 10 faktor yang mempengaruhi keterikatan karyawan (employee engagement) 
terhadap perusahaan, yaitu connect, career, clarity, convey, congratulate, contribute, control, collaborate, credibility, dan confidence.

Selain Crim dan Seijts (2006), seorang peneliti bernama Gallup telah memantau penurunan employee engagement tahun 2011 dengan menghubungkan skor engagement yang rendah pada kurangnya manajemen kinerja internal. Gallup yang memiliki organisasi survei menggunakan Q12 yaitu 12 pertanyaan survei yang bertujuan untuk mengidentifikasi elemen-elemen karyawan yang terikat (engage) terhadap pekerjaan dan perusahaannya. Hasil survei menunjukkan korelasi yang cukup kuat antara pencapaian kinerja yang tinggi dan penilaian hasil survei yang tinggi.

Berdasarkan survei yang telah dilakukan sejak bulan Agustus 2015, Gallup melaporkan setidaknya terdapat pencapaian engagement sebesar $30 \%$ setiap bulan di Amerika Serikat. Hasil survei terkini yang telah dilakukan oleh Gallup pada bulan April 2016 menyimpulkan bahwa 33\% dari karyawan yang disurvei telah 'terlibat secara aktif', sementara sebanyak 50\% 'tidak terlibat', dan sisanya sebesar $17 \%$ tidak terlibat secara aktif'.

Sampai saat ini, penelitian terkait pengaruh employee engagement terhadap kinerja merupakan tema yang menarik dan masih hangat dibahas di lingkungan bisnis. Persamaan penelitian terdahulu yang dilakukan oleh Crim dan Seijts (2006) dengan penelitian yang akan dilakukan di sini adalah sama-sama meneliti tentang employee engagement dengan menggunakan dasar teori yang sama. Namun, perbedaan antara penelitian ini dan penelitian terdahulu yang telah dilakukan oleh Crim dan Seijts (2006), yaitu penelitian Crim dan Seijts (2006) meneliti employee engagement pada perusahaan, sedangkan penelitian ini mengkaji pengaruh employee engagement terhadap kinerja karyawan yang melibatkan variabel lain di dalamnya.

\section{HIPOTESIS}

Berdasarkan teori dan analisis di atas, maka peneliti mengajukan hipotesis dalam penelitian ini sebagai berikut:

$\mathrm{H}_{1}$ : Terdapat pengaruh positif dan signifikan antara employee engagement terhadap kinerja karyawan Program D3 Fakultas Ekonomi Universitas Islam Indonesia Yogyakarta.

$\mathrm{H}_{2}$ : Faktor collaborate merupakan faktor yang paling dominan mempengaruhi kinerja karyawan Program D3 Fakultas Ekonomi Universitas Islam Indonesia Yogyakarta.

\section{METODE PENELITIAN}

Penelitian yang dilakukan ini adalah jenis penelitian survei yang mengumpulkan informasi dengan menggunakan kuesioner. Dalam penelitian ini terdapat dua jenis variabel, yaitu variabel bebas (independent variable) dan variabel terikat (dependent variable). Ada pun variabel terikat dalam penelitian ini adalah variabel kinerja karyawan (employee performance). Variabel terikat tersebut adalah variabel yang dipengaruhi atau yang menjadi akibat adanya variabel bebas (Sugiyono, 2006: 3). Variabel dependen yang akan diuji dalam penelitian ini adalah kinerja karyawan Program D3 FE UII Yogyakarta. Ada pun variabel bebas dalam penelitian ini adalah variabel employee engagement. Variabel bebeas adalah variabel yang mempengaruhi atau menjadi sebab timbulnya variabel terikat (Sugiyono, 2006: 3). Dalam penelitian ini, variabel independen yang akan diuji adalah employee engagement karyawan Program D3 FE UII Yogyakarta. 


\section{DEFINISI OPERASIONAL VARIABEL}

\section{Employee Engagement}

Menurut hasil penelitian yang dilakukan oleh tim peneliti dari Kingston University pada tahun 2008, Engagement adalah keterikatan yang dibangun pada tingkat individu dan jika menyebabkan hasil bisnis, itu harus mempengaruhi hasil tingkat individu. Oleh karena itu, ada alasan untuk mengharapkan keterlibatan karyawan berhubungan dengan sikap individu, niat, dan perilaku. Tim Rutledge menjelaskan bahwa karyawan yang benar-benar terikat/terlibat merupakan karyawan yang tertarik dan terinsipirasi oleh: pekerjaan mereka ("saya ingin melakukan ini"), berkomitmen ("saya mendedikasikan keberhasilan untuk apa yang telah saya lakukan"), dan terpesona ("saya mencintai apa yang saya lakukan"). Employee Engagement juga berkaitan dengan faktor kepemimpinan yang efektif. Crim dan Seijts (2006) menyimpulkan bahwa terdapat 10 faktor yang mempengaruhi keterikatan karyawan (employee engagement) terhadap perusahaan, yaitu connect, career, clarity, convey, congratulate, contribute, control, collaborate, credibility, dan confidence.

\section{Kinerja Karyawan}

Kinerja karyawan adalah hasil dari pekerjaan yang terkait dengan tujuan organisasi, efisiensi, dan keefektifan kinerja lainnya (Gibson et al., 1997). Menurut Bernardin (2010) terdapat enam kriteria untuk menilai kinerja karyawan, yaitu:

a. Quality

Quality merupakan tingkatan di mana proses atau penyesuaian pada cara yang ideal dalam melakukan aktivitas atau memenuhi aktivitas yang sesuai harapan.

b. Quantity

Quantity adalah jumlah yang dihasilkan dan diwujudkan melalui nilai mata uang, jumlah unit, atau jumlah dari siklus aktivitas yang telah diselesaikan.

c. Timeliness

Timeliness merupakan tingkatan di mana aktivitas telah diselesaikan dengan waktu yang lebih cepat dari yang ditentukan dan memaksimalkan waktu yang ada untuk aktivitas lain.

d. Cost Effectiveness

Cost effectiveness merupakan tingkatan di mana penggunaan sumber daya perusahaan yang berupa manusia, keuangan, dan teknologi dimaksimalkan untuk mendapatkan hasil yang tertinggi atau pengurangan kerugian dari tiap unit.

e. Need for supervision

Need for supervisionmerupakan tingkatan di mana seorang karyawan dapat melakukan pekerjaannya tanpa perlu meminta pertolongan atau bimbingan dari atasannya.

f. Interpersonal impact

Interpersonal impact merupakan tingkatan di mana seorang karyawan merasa percaya diri, memiliki keinginan yang baik, dan bekerja sama diantara rekan kerja.

\section{POPULASI DAN SAMPEL}

Populasi adalah wilayah generalisasi yang terdiri atas obyek/subyek yang mempunyai kuantitas dan karakteristik tertentu yang ditetapkan untuk dipelajari dan 
kemudian ditarik kesimpulannya (Sugiyono, 2006: 55). Populasi dalam penelitian ini adalah seluruh karyawan Program D3 FE UII Yogyakarta.

\section{Sampel}

Sampel adalah sebagian dari jumlah dan karakteristik yang dimiliki oleh populasi tersebut (Sugiyono, 2006: 56). Pada penelitian ini teknik sampling yang digunakan adalah metode convenience sampling yaitu metode memilih sampel dari elemen populasi yang mudah diperoleh datanya (Supomo \& Indriantoro, 1999). Sampel yang diambil adalah seluruh karyawan yang bekerja di Program D3 FE UII Yogyakarta, yang cocok digunakan untuk sumber data dan bersedia mengisi kuesioner tentang kinerja karyawan di Program D3 FE UII.

\section{a. Teknik Pengumpulan Data}

Adapun metode pengumpulan data yang digunakan dalam penelitian ini adalah Quetionairre (angket). Pengumpulan data lapangan dengan memberikan pernyataan favorable (pernyataan positif) melalui media tertulis (cetakan) kepada responden. Pada penelitian ini, kuesioner yang disebarkan merupakan kuesioner yang telah disesuaikan dengan teori yang digunakan dalam penelitian ini.

\section{b. Alat Analisis Data Penelitian}

\section{Analisis Deskriptif:}

a. Memberikan gambaran umum responden dengan persentase

b. Penilaian terhadap variabel penelitian, didasarkan pada rata-rata setiap item pernyataan baik pada variabel variabel Employee Engagement (X), Kinerja Karyawan (Y). Sebelum dilakukan analisis lebih lanjut, terlebih dahulu dilakukan pengkategorian untuk menentukan penilaian yang rendah dan tinggi pada seluruh variabel. Pengkategorian ini didasarkan pada penilaian terendah yaitu 1 (sangat tidak setuju), dan skor tertinggi adalah 5 (sangat setuju) yang mengacu pada Skala Likert. Kriteria masing-masing penilaiannya adalah sebagai berikut:

Variabel Employee Engagement (X)

Skor minimum $=1$ dan Skor maksimum $=5$ maka Interval $=(5-1): 2=2$ sehingga diperoleh kriteria persepsi sebagai berikut:

$1,00-3,00=$ tidak sesuai

$3,00-5,00=$ sesuai

Kinerja Karyawan (Y)

Skor minimum $=1$ dan Skor maksimum $=5$ maka Interval $=(5-1): 5=0,8$

sehingga diperoleh kriteria persepsi sebagai berikut:

$$
\begin{aligned}
1,00-1,80 & =\text { Sangat Rendah } \\
1,81-2,60 & =\text { Rendah } \\
2,60-3,40 & =\text { Sedang } \\
3,40-4,20 & =\text { Tinggi } \\
4,20-5,00 & =\text { Sangat Tinggi }
\end{aligned}
$$

\section{Analisis kuantitatif: digunakan Analisis Regresi}

Pengujian hipotesis dalam penelitian ini dilakukan dengan menggunakan Model Regresi Linear Berganda. Penggunaan teknik regresi linear berganda (multiple linear regression) bertujuan untuk mengetahui pengaruh variabel independen (X) terhadap variabel dependen (Y) (Cooper, Schindler, 2008).

Model Regresi Linear Berganda merupakan metode statistika yang dipakai untuk mengetahui pola hubungan antar variabel. Model regresi ini terdiri lebih dari satu variabel independen. Adapun bentuk umum regresi linear berganda: 
Keterangan:

$$
Y=\beta_{0}+\beta_{1} X_{1}+\beta_{2} X_{2}+\beta_{3} X_{3}+\ldots+\beta_{10} X_{10}+e
$$

$Y \quad$ : kinerja karyawan (employee performance)

$X_{1}:$ Connect $\quad X_{6}:$ Contribute

$X_{2}:$ Career $\quad X_{7}:$ Control

$X_{3}:$ Clarity $\quad X_{8}:$ Collaborate

$X_{4}:$ Convey $\quad X_{9}:$ Credibility

$X_{5}:$ Congratulate $\quad X_{10}$ : Confidence

$\beta_{\mathrm{i}} \quad$ : koefisien regresi variabel $X_{i}(\mathrm{i}=1,2,3 \ldots \ldots \ldots . .10)$

$\beta_{0}$ : bilangan konstan

$e \quad$ : kesalahan (error)

Untuk menilai apakah model regresi yang dihasilkan merupakan model yang paling sesuai (memiliki eror terkecil), dibutuhkan beberapa pengujian dan analisis di antaranya adalah uji t, uji F serta uji asumsi klasik yang mencakup uji multikolinearitas, uji heterokedastisitas dan uji autokorelasi. Ada pun definisi masing-masing pengujian dijelaskan berikut ini.

\section{Uji t (Parsial)}

Uji t merupakan pengujian masing-masing variabel independen yang dilakukan untuk mengetahui apakah secara individu variabel independen berpengaruh signifikan terhadap variabel dependen. Pengujian ini dapat dilakukan dengan membandingkan hasil dari t hitung dengan t tabel atau dapat juga dilakukan dengan membandingkan probabilitasnya pada derajat keyakinan tertentu.

Jika t-hitung $\leq \mathrm{t}$-tabel, maka $\mathrm{H}_{0}$ diterima dan $\mathrm{H}_{\mathrm{a}}$ ditolak. Artinya, variabel independen tidak mempengaruhi variabel dependen secara signifikan. Sebaliknya, jika Jika t-hitung $>$ t-tabel, maka $\mathrm{H}_{0}$ ditolak dan $\mathrm{H}_{\mathrm{a}}$ diterima. Artinya, variabel independen berpengaruh terhadap variabel dependen secara signifikan.

Apabila dibandingkan dengan probabilitas pada derajat keyakinan 5\%, maka jika probabilitas $<0,05$ berarti variabel independen berpengaruh terhadap variabel dependen secara signifikan. Sebaliknya, jika probabilitas $\geq 0,05$ berarti variabel independen tidak mempengaruhi variabel dependen secara signifikan.

\section{Uji F (Serempak)}

Pengujian ini bertujuan untuk mengetahui pengaruh variabel independen secara bersama-sama terhadap variabel dependen.

Jika F-hitung $\leq$ F-tabel, maka $\mathrm{H}_{0}$ diterima dan $\mathrm{H}_{\mathrm{a}}$ ditolak. Artinya, secara bersama-sama variabel independen tidak mempengaruhi variabel dependen secara signifikan. Sebaliknya, jika F-hitung $>$ F-tabel, maka $\mathrm{H}_{0}$ ditolak dan $\mathrm{H}_{\mathrm{a}}$ diterima. Artinya, secara bersama-sama variabel independen berpengaruh terhadap variabel dependen secara signifikan.

Apabila dibandingkan dengan probabilitas pada derajat keyakinan 5\%, maka jika probabilitas $<0,05$ berarti variabel independen secara bersama-sama berpengaruh terhadap variabel dependen secara signifikan. Sebaliknya, jika probabilitas $\geq 0,05$ berarti variabel independen secara bersama-sama tidak mempengaruhi variabel terhadap variabel dependen secara signifikan. 


\section{HASIL PENELITIAN DAN PEMBAHASAN}

\section{Analisis Diskriptif}

Dalam penelitian ini, data yang diperoleh berasal dari karyawan Program Diploma III Fakultas Ekonomi Universitas Islam Indonesia Yogyakarta melalui penyebaran kuesioner sebanyak 13 responden. Dari penyebaran kuesioner kepada 13 responden dapat diketahui gambaran (profil) responden karyawan Program Diploma III Fakultas Ekonomi Universitas Islam Indonesia Yogyakarta, sebagian besar responden berasal dari unit kerja di Bagian Akademik sebanyak enam orang (46\%) yang terbagi ke dalam sub unit yaitu di Bagian Pelayanan Nilai, Perkuliahan, Teknologi Informasi, dan Presensi. Sisa responden berasal dari berbagai unit kerja dengan rata-rata karyawan sebanyak 2-3 orang (15\%-23\%). Sebagian besar responden memiliki masa kerja lebih dari 10 tahun sebanyak $46 \%$ atau enam orang. Responden dengan masa kerja $1-5$ tahun sebanyak 5 orang (39\%), sedangkan untuk responden dengan masa kerja kurang dari 1 tahun sebanyak 2 orang (15\%).

\section{Diskripsi Variabel Penelitian}

\section{a. Variabel employee engagement $(\mathrm{X})$}

Pada variabel employee engagement yang terdiri atas variabel connect $\left(\mathrm{X}_{1}\right)$, career $\left(\mathrm{X}_{2}\right)$, clarity $\left(\mathrm{X}_{3}\right)$, convey $\left(\mathrm{X}_{4}\right)$, congratulate $\left(\mathrm{X}_{5}\right)$, contribute $\left(\mathrm{X}_{6}\right)$, control $\left(\mathrm{X}_{7}\right)$, collaborate $\left(\mathrm{X}_{8}\right)$, credibility $\left(\mathrm{X}_{9}\right)$, dan confidence $\left(\mathrm{X}_{10}\right)$, maka diperoleh hasil:

Tabel 1. Analisis Diskriptif Connect $\left(\mathrm{X}_{1}\right)$

\begin{tabular}{|c|l|r|r|l|}
\hline No & \multicolumn{1}{|c|}{ Item Pernyataan } & Rerata & \multicolumn{1}{c|}{$\%$} & Kategori \\
\hline 1 & $\begin{array}{l}\text { Pemimpin mampu membangun hubungan } \\
\text { hormat dengan karyawan }\end{array}$ & 4,31 & 37,09 & Sesuai \\
\hline 2 & $\begin{array}{l}\text { Pemimpin mengetahui kapan peristiwa } \\
\text { perubahan hidup mempengaruhi karyawan }\end{array}$ & 3,31 & 28,48 & Sesuai \\
\hline 3 & $\begin{array}{l}\text { Pemimpin mampu berbagi waktu untuk umpan } \\
\text { balik pada saat berbagi keprihatinan. }\end{array}$ & 4,00 & 34,43 & Sesuai \\
\hline \multicolumn{2}{|l|}{ TOTAL } & $\mathbf{1 1 , 6 2}$ & $\mathbf{1 0 0}$ & - \\
\hline \multicolumn{2}{|l}{ Total Mean/jumlah item } & $\mathbf{3 , 8 7}$ & - & Sesuai \\
\hline
\end{tabular}

Sumber: data primer diolah.

Dari tabel di atas dapat diketahui secara kumulatif bahwa dari 13 responden yang digunakan, responden memberikan penilaian sesuai terhadap pernyataan yang terkait dengan variabel Connect $\left(\mathrm{X}_{1}\right)$ dengan rata-rata sebesar 3,87 dan berada pada kriteria sesuai. Hal ini berarti bahwa Connect yang diberikan telah sesuai dengan kriteria Employee Engagement.

Dari tabel di bawah dapat diketahui secara kumulatif bahwa dari 13 responden yang diambil, responden memberikan penilaian sesuai terhadap pernyataan yang terkait dengan variabel Career $\left(\mathrm{X}_{2}\right)$ dengan rata-rata sebesar 4,00 dan berada pada kriteria sesuai. Hal ini berarti bahwa Career yang diberikan telah sesuai dengan kriteria Employee Engagement. 
Tabel 2. Analisis Deskriptif Career $\left(\mathbf{X}_{2}\right)$

\begin{tabular}{|c|l|r|r|l|}
\hline No & \multicolumn{1}{|c|}{ Item Pernyataan } & \multicolumn{1}{c|}{ Rerata } & \multicolumn{1}{c|}{$\%$} & \multicolumn{1}{c|}{ Kategori } \\
\hline 1 & $\begin{array}{l}\text { Pemimpin bersedia untuk duduk bersama dan } \\
\text { memahami tujuan karir dari karyawan }\end{array}$ & 4,08 & 33,97 & Sesuai \\
\hline 2 & $\begin{array}{l}\text { Pemimpin mendorong orang lain untuk terlibat } \\
\text { belajar }\end{array}$ & 4,00 & 33,33 & Sesuai \\
\hline 3 & $\begin{array}{l}\text { Pemimpin mencari peluang pertumbuhan untuk } \\
\text { diri sendiri dan tim. }\end{array}$ & 3,92 & 32,69 & Sesuai \\
\hline \multicolumn{2}{|c|}{ TOTAL } & $\mathbf{1 2 , 0 0}$ & $\mathbf{1 0 0}$ & - \\
\hline \multicolumn{2}{|c|}{ Total Mean/jumlah item } & $\mathbf{4 , 0 0}$ & - & Sesuai \\
\hline
\end{tabular}

Sumber: data primer diolah.

Tabel 3. Analisis Deskriptif Clarity $\left(\mathbf{X}_{3}\right)$

\begin{tabular}{|l|l|r|r|l|}
\hline \multicolumn{1}{|c|}{ No } & \multicolumn{1}{|c|}{ Item Pernyataan } & \multicolumn{1}{c|}{ Rerata } & \multicolumn{1}{c|}{$\%$} & \multicolumn{1}{c|}{ Kategori } \\
\hline 1. & $\begin{array}{l}\text { Pemimpin berbagi tujuan dan strategi yang } \\
\text { penting untuk mencapai tim }\end{array}$ & 3,69 & 33,57 & Sesuai \\
\hline 2. & $\begin{array}{l}\text { Pemimpin memastikan rencana memiliki tingkat } \\
\text { detail yang menghindari kesenjangan }\end{array}$ & 3,69 & 33,57 & Sesuai \\
\hline 3. & $\begin{array}{l}\text { Pemimpin memastikan karyawan memahami } \\
\text { dengan jelas ruang lingkup dan tugasnya. }\end{array}$ & 3,62 & 32,87 & Sesuai \\
\hline TOTAL & $\mathbf{1 1 , 0 0}$ & $\mathbf{1 0 0}$ & - \\
\hline \multicolumn{2}{|l|}{ Total Mean/jumlah item } & $\mathbf{3 , 6 7}$ & - & Sesuai \\
\hline
\end{tabular}

Sumber: data primer diolah.

Dari tabel di atas dapat diketahui secara kumulatif bahwa dari 13 responden yang diambil, responden memberikan penilaian sesuai terhadap pernyataan yang terkait dengan variabel Clarity $\left(\mathrm{X}_{3}\right)$ dengan rata-rata sebesar 3,67 dan berada pada kriteria sesuai. Hal ini berarti bahwa Clarity yang diberikan telah sesuai dengan kriteria Employee Engagement.

Tabel 4. Analisis Deskriptif Convey $\left(\mathrm{X}_{4}\right)$

\begin{tabular}{|c|l|r|r|l|}
\hline No & \multicolumn{1}{|c|}{ Item Pernyataan } & Rerata & \multicolumn{1}{c|}{$\%$} & Kategori \\
\hline 1 & $\begin{array}{l}\text { Pemimpin merencanakan waktu untuk } \\
\text { mendengarkan dan menerima/memberikan } \\
\text { umpan balik. }\end{array}$ & 3,62 & 35,34 & Sesuai \\
\hline 2 & $\begin{array}{l}\text { Pemimpin memberikan meng-update tujuan dan } \\
\text { status tindak lanjut }\end{array}$ & 3,23 & 31,58 & Sesuai \\
\hline 3 & $\begin{array}{l}\text { Pemimpin mampu berbagi informasi terkait } \\
\text { tanda-tanda tepat waktu, insiden, dan inisiatif } \\
\text { baru. }\end{array}$ & 3,38 & 33,08 & Sesuai \\
\hline TOTAL & $\mathbf{1 0 , 2 3}$ & $\mathbf{1 0 0}$ & - \\
\hline \multicolumn{2}{|l|}{ Total Mean/jumlah item } & $\mathbf{3 , 4 1}$ & - & Sesuai \\
\hline
\end{tabular}

Sumber: data primer diolah.

Dari tabel di atas dapat diketahui secara kumulatif bahwa dari 13 responden yang diambil, responden memberikan penilaian sesuai terhadap pernyataan yang terkait dengan variabel Convey $\left(\mathrm{X}_{4}\right)$ dengan rata-rata sebesar 3,41 dan berada pada kriteria sesuai. Hal ini berarti bahwa Convey yang diberikan telah sesuai dengan kriteria Employee Engagement. 
Tabel 5. Analisis Deskriptif Congratulate $\left(\mathrm{X}_{5}\right)$

\begin{tabular}{|c|l|r|r|l|}
\hline No & \multicolumn{1}{|c|}{ Item Pernyataan } & \multicolumn{1}{c|}{ Rerata } & \multicolumn{1}{c|}{$\%$} & \multicolumn{1}{c|}{ Kategori } \\
\hline 1 & $\begin{array}{l}\text { Pemimpin berterimakasih kepada karyawan } \\
\text { karena melakukan hal yang benar/sesuai }\end{array}$ & 3,39 & 33,59 & Sesuai \\
\hline 2 & $\begin{array}{l}\text { Pemimpin menunjukkan penghargaan bagi } \\
\text { karyawan yang mau bekerja secara sukarela }\end{array}$ & 3,46 & 34,35 & Sesuai \\
\hline 3 & $\begin{array}{l}\text { Pemimpin mampu melacak dan mengenali kunci } \\
\text { milestones dan prestasi. }\end{array}$ & 3,23 & 33,06 & Sesuai \\
\hline \multicolumn{2}{|l|}{ TOTAL } & $\mathbf{1 0 , 0 8}$ & $\mathbf{1 0 0}$ & - \\
\hline \multicolumn{2}{|l|}{ Total Mean/jumlah item } & $\mathbf{3 , 3 6}$ & - & Sesuai \\
\hline
\end{tabular}

Sumber: data primer diolah.

Dari tabel di atas dapat diketahui secara kumulatif bahwa dari 13 responden yang diambil, responden memberikan penilaian sesuai terhadap pernyataan yang terkait dengan variabel Congratulate $\left(\mathrm{X}_{5}\right)$ dengan rata-rata sebesar 3,36 dan berada pada kriteria sesuai. Hal ini berarti bahwa Congratulate yang diberikan telah sesuai dengan kriteria Employee Engagement.

Tabel 6. Analisis Deskriptif Contribute $\left(\mathrm{X}_{6}\right)$

\begin{tabular}{|c|l|r|r|l|}
\hline No & \multicolumn{1}{|c|}{ Item Pernyataan } & \multicolumn{1}{c|}{ Rerata } & \multicolumn{1}{c|}{$\%$} & \multicolumn{1}{c|}{ Kategori } \\
\hline 1 & $\begin{array}{l}\text { Pemimpin berterimakasih kepada karyawan } \\
\text { karena melakukan hal yang benar/sesuai }\end{array}$ & 3,46 & 31,91 & Sesuai \\
\hline 2 & $\begin{array}{l}\text { Pemimpin menunjukkan penghargaan bagi } \\
\text { karyawan yang mau bekerja secara sukarela }\end{array}$ & 3,85 & 35,46 & Sesuai \\
\hline 3 & $\begin{array}{l}\text { Pemimpin mampu melacak dan mengenali kunci } \\
\text { milestones dan prestasi. }\end{array}$ & 3,54 & 32,62 & Sesuai \\
\hline TOTAL & $\mathbf{1 0 , 8 4}$ & $\mathbf{1 0 0}$ & - \\
\hline \multicolumn{2}{|l|}{ Total Mean/jumlah item } & $\mathbf{3 , 6 2}$ & - & Sesuai \\
\hline
\end{tabular}

Sumber: data primer diolah

Dari tabel di atas dapat diketahui secara kumulatif bahwa dari 13 responden yang diambil, responden memberikan penilaian sesuai terhadap pernyataan yang terkait dengan variabel Contribute $\left(\mathrm{X}_{6}\right)$ dengan rata-rata sebesar 3,62 dan berada pada kriteria sesuai. Hal ini berarti bahwa Contribute yang diberikan telah sesuai dengan kriteria Employee Engagement.

Tabel 7. Analisis Deskriptif Control $\left(\mathrm{X}_{7}\right)$

\begin{tabular}{|c|l|r|r|l|}
\hline No & \multicolumn{1}{|c|}{ Item Pernyataan } & \multicolumn{1}{c|}{ Rerata } & \multicolumn{1}{c|}{$\%$} & Kategori \\
\hline 1 & $\begin{array}{l}\text { Pemimpin meminta partisipasi karyawan dalam } \\
\text { tujuan, prosedur, dan perencanaan }\end{array}$ & 3,46 & 34,09 & Sesuai \\
\hline 2 & $\begin{array}{l}\text { Pemimpin meminta kritik dan bertindak atas } \\
\text { saran perbaikan }\end{array}$ & 3,46 & 34,09 & Sesuai \\
\hline 3 & $\begin{array}{l}\text { Pemimpin mampu menjaga karyawan tetap } \\
\text { dalam lingkaran kendalinya dan memperbarui } \\
\text { status karyawan. }\end{array}$ & 3,23 & 31,28 & Sesuai \\
\hline TOTAL & $\mathbf{1 0 , 1 5}$ & $\mathbf{1 0 0}$ & - \\
\hline Total Mean/jumlah item & $\mathbf{3 , 3 8}$ & - & Sesuai \\
\hline
\end{tabular}

Sumber: data primer diolah. 
Dari tabel di atas dapat diketahui secara kumulatif bahwa dari 13 responden yang diambil, responden memberikan penilaian sesuai terhadap pernyataan yang terkait dengan variabel Control $\left(\mathrm{X}_{7}\right)$ dengan rata-rata sebesar 3,38 dan berada pada kriteria sesuai. Hal ini berarti bahwa Control yang diberikan telah sesuai dengan kriteria Employee Engagement.

Tabel 8. Analisis Deskriptif Collaborate $\left(\mathrm{X}_{8}\right)$

\begin{tabular}{|c|l|r|r|l|}
\hline No & \multicolumn{1}{|c|}{ Item Pernyataan } & \multicolumn{1}{c|}{ Rerata } & \multicolumn{1}{c|}{$\%$} & \multicolumn{1}{c|}{ Kategori } \\
\hline 1 & $\begin{array}{l}\text { Pemimpin meminta partisipasi karyawan dalam } \\
\text { tujuan, prosedur, dan perencanaan }\end{array}$ & 3,39 & 30,99 & Sesuai \\
\hline 2 & $\begin{array}{l}\text { Pemimpin meminta kritik dan bertindak atas } \\
\text { saran perbaikan }\end{array}$ & 3,86 & 35,21 & Sesuai \\
\hline 3 & $\begin{array}{l}\text { Pemimpin mampu menjaga karyawan tetap } \\
\text { dalam lingkaran kendalinya dan memperbarui } \\
\text { status karyawan. }\end{array}$ & 3,69 & 33,80 & Sesuai \\
\hline TOTAL & $\mathbf{1 0 , 9 2}$ & $\mathbf{1 0 0}$ & - \\
\hline \multicolumn{2}{|l}{ Total Mean/jumlah item } & $\mathbf{3 , 6 4}$ & - & Sesuai \\
\hline
\end{tabular}

Sumber: data primer diolah.

Dari tabel di atas dapat diketahui secara kumulatif bahwa dari 13 responden yang diambil, responden memberikan penilaian sesuai terhadap pernyataan yang terkait dengan variabel Collaborate $\left(\mathrm{X}_{8}\right)$ dengan rata-rata sebesar 3,64 dan berada pada kriteria sesuai. Hal ini berarti bahwa Collaborate yang diberikan telah sesuai dengan kriteria Employee Engagement.

Tabel 9. Analisis Deskriptif Credibility (X9)

\begin{tabular}{|c|l|r|r|l|}
\hline No & \multicolumn{1}{|c|}{ Item Pernyataan } & \multicolumn{1}{c|}{ Rerata } & \multicolumn{1}{c|}{$\%$} & \multicolumn{1}{c|}{ Kategori } \\
\hline 1 & $\begin{array}{l}\text { Pemimpin secara konsisten menunjukkan apa } \\
\text { yang dikatakan atau dilatih }\end{array}$ & 3,39 & 31,43 & Sesuai \\
\hline 2 & $\begin{array}{l}\text { Pemimpin mampu bereaksi dengan cara yang } \\
\text { hormat bahkan di saat marah }\end{array}$ & 3,54 & 32,86 & Sesuai \\
\hline 3 & $\begin{array}{l}\text { Pemimpin mampu bertanggung jawab atas } \\
\text { kesalahan atau kegagalannya. }\end{array}$ & 3,85 & 35,71 & Sesuai \\
\hline TOTAL & $\mathbf{1 0 , 7 7}$ & $\mathbf{1 0 0}$ & - \\
\hline \multicolumn{2}{|l|}{ Total Mean/jumlah item } & $\mathbf{3 , 5 9}$ & - & Sesuai \\
\hline
\end{tabular}

Sumber: data primer diolah.

Dari tabel di atas dapat diketahui secara kumulatif bahwa dari 13 responden yang diambil, responden memberikan penilaian sesuai terhadap pernyataan yang terkait dengan variabel Credibility $\left(\mathrm{X}_{9}\right)$ dengan rata-rata sebesar 3,59 dan berada pada kriteria sesuai. Hal ini berarti bahwa Credibility yang diberikan telah sesuai dengan kriteria Employee Engagement.

Dari tabel di bawah dapat diketahui secara kumulatif bahwa dari 13 responden yang diambil, responden memberikan penilaian sesuai terhadap pernyataan yang terkait dengan variabel Confident $\left(\mathrm{X}_{10}\right)$ dengan rata-rata sebesar 3,51 dan berada pada kriteria sesuai. Hal ini berarti bahwa Confident yang diberikan telah sesuai dengan kriteria Employee Engagement. 
Tabel 10. Analisis Deskriptif Confident $\left(\mathrm{X}_{10}\right)$

\begin{tabular}{|c|l|r|r|l|}
\hline No & \multicolumn{1}{|c|}{ Item Pernyataan } & \multicolumn{1}{c|}{ Rata $^{\mathbf{2}}$} & \multicolumn{1}{c|}{$\%$} & Kategori \\
\hline 1 & $\begin{array}{l}\text { Pemimpin mampu memberikan pesan yang } \\
\text { konsisten tentang hal-hal penting }\end{array}$ & 3,23 & 30,66 & Sesuai \\
\hline 2 & $\begin{array}{l}\text { Pemimpin mampu mengumpulkan kembali upaya } \\
\text { untuk mendorong suatu hal setelah insiden }\end{array}$ & 3,54 & 33,58 & Sesuai \\
\hline 3 & $\begin{array}{l}\text { Pemimpin mampu menjalani dan melatih } \\
\text { keselamatan sebagai nilai inti di dalam maupun } \\
\text { di luar pekerjaan. }\end{array}$ & 3,77 & 35,77 & Sesuai \\
\hline \multicolumn{2}{|l|}{ TOTAL } & $\mathbf{1 0 , 5 4}$ & $\mathbf{1 0 0}$ & - \\
\hline \multicolumn{2}{|l}{ Total Mean/jumlah item } & $\mathbf{3 , 5 1}$ & - & Sesuai \\
\hline
\end{tabular}

Sumber: data primer diolah.

\section{Variabel Kinerja Karyawan (Y)}

Variabel kinerja karyawan (Y) diukur dengan 18 pertanyaan dan penjelasan mengenai jawaban responden tersebut diperoleh hasil berikut ini:

Tabel 11. Analisis Deskriptif Kinerja Karyawan (Y)

\begin{tabular}{|c|c|c|c|c|}
\hline No & Item Pernyataan & Rerata & $\%$ & Kategori \\
\hline 1 & $\begin{array}{l}\text { Karyawan mampu melayani mahasiswa/dosen } \\
\text { dengan cepat }\end{array}$ & 3,77 & 5,33 & Tinggi \\
\hline 2 & $\begin{array}{l}\text { Karyawan mampu memberikan layanan yang baik } \\
\text { kepada mahasiswa/dosen }\end{array}$ & 4,00 & 5,65 & Tinggi \\
\hline 3 & $\begin{array}{l}\text { Karyawanmampu menghasilkan pekerjaan yang } \\
\text { selalu terjamin mutunya }\end{array}$ & 3,77 & 5,33 & Tinggi \\
\hline 4 & $\begin{array}{l}\text { Karyawan mampu melakukan pekerjaan sesuai } \\
\text { dengan metode kerja. }\end{array}$ & 3,62 & 5,11 & Tinggi \\
\hline 5 & $\begin{array}{l}\text { Karyawan mampu memenuhi target pekerjaan } \\
\text { dalam } 1 \text { (satu) hari. }\end{array}$ & 3,31 & 4,67 & Sedang \\
\hline 6 & $\begin{array}{l}\text { Karyawan mampu menggunakan perangkat dan alat } \\
\text { kerja dengan efektif dan efisien sesuai dengan } \\
\text { kebutuhan. }\end{array}$ & 3,46 & 4,89 & Tinggi \\
\hline 7 & $\begin{array}{l}\text { Karyawanmampu bekerja sampai waktu yang telah } \\
\text { ditentukan. }\end{array}$ & 4,15 & 5,87 & Tinggi \\
\hline 8 & $\begin{array}{l}\text { Karyawan selalu datang ke tempat kerja tepat } \\
\text { waktu. }\end{array}$ & 3,23 & 4,57 & Sedang \\
\hline 9 & $\begin{array}{l}\text { Waktu karyawan dalam melayani mahasiswa dan } \\
\text { dosen sesuai ketentuan. }\end{array}$ & 3,92 & 5,54 & Tinggi \\
\hline 10 & $\begin{array}{l}\text { Karyawan mampu menggunakan sumber daya yang } \\
\text { berupa keuangan dan teknologi untuk mengurangi } \\
\text { kerugian. }\end{array}$ & 3,77 & 5,33 & $\begin{array}{l}\text { Sangat } \\
\text { Tinggi }\end{array}$ \\
\hline 11 & $\begin{array}{l}\text { Karyawan mampu meminimalisir kesalahan dalam } \\
\text { membuat konsep surat dan cetakan laporan. }\end{array}$ & 4,23 & 5,98 & $\begin{array}{l}\text { Sangat } \\
\text { Tinggi }\end{array}$ \\
\hline 12 & $\begin{array}{l}\text { Karyawan mampu membuat mekanisme kerja dan } \\
\text { menyusun skala prioritas terkait pekerjaan sehari- } \\
\text { hari. }\end{array}$ & 4,15 & 5,87 & Tinggi \\
\hline 13 & $\begin{array}{l}\text { Karyawan mampu berkomunikasi dengan atasan } \\
\text { ketika tidak dapat datang ke tempat kerja (absen). }\end{array}$ & 4,46 & 6,30 & $\begin{array}{l}\text { Sangat } \\
\text { Tinggi }\end{array}$ \\
\hline 14 & $\begin{array}{l}\text { Karyawan mampu menyelesaikan tugas yang } \\
\text { didelegasikan atasan dengan benar dan tepat waktu } \\
\text { sesuai deadline tanpa arahan atasan. }\end{array}$ & 4,31 & 6,09 & $\begin{array}{l}\text { Sangat } \\
\text { Tinggi }\end{array}$ \\
\hline
\end{tabular}




\begin{tabular}{|c|c|c|c|c|}
\hline 15 & $\begin{array}{l}\text { Karyawan memiliki inisiatif yang tinggi terhadap } \\
\text { pekerjaan atau permasalahan yang belum } \\
\text { terselesaikan (belum ada solusi). }\end{array}$ & 4,08 & 5,76 & Tinggi \\
\hline 16 & $\begin{array}{l}\text { Karyawanmampu bekerjasama dengan rekan kerja } \\
\text { dalam mengerjakan pekerjaan. }\end{array}$ & 4,23 & 5,98 & $\begin{array}{l}\text { Sangat } \\
\text { Tinggi }\end{array}$ \\
\hline 17 & $\begin{array}{l}\text { Hubungan antar karyawan di semua unit sangat } \\
\text { baik. }\end{array}$ & 4,08 & 5,76 & Tinggi \\
\hline 18 & $\begin{array}{l}\text { Karyawan memiliki rasa kepercayaan diri yang } \\
\text { tinggi terhadap kompetensi yang dimiliki dan saling } \\
\text { menghormati dengan tidak merendahkan rekan } \\
\text { sekerjanya. }\end{array}$ & 4,23 & 5,98 & $\begin{array}{l}\text { Sangat } \\
\text { Tinggi }\end{array}$ \\
\hline \multicolumn{2}{|c|}{ TOTAL } & 70,77 & 100 & - \\
\hline \multicolumn{2}{|c|}{ Total Mean/jumlah item } & 3,93 & - & Tinggi \\
\hline
\end{tabular}

Sumber: data primer diolah.

Dari data tersebut di atas dapat diketahui secara kumulatif bahwa sebanyak dari 13 responden menyatakan setuju terhadap pernyataan kinerja karyawan yang dikemukakan oleh peneliti dengan rata-rata sebesar 3,93. Rata-rata tersebut masuk dalam kategori tinggi sehingga dikatakan bahwa kinerja karyawan tinggi.

Tabel 12. Hasil Analisis Regresi Berganda Variabel $X_{1}, X_{2}, X_{3}, X_{4}, X_{5}, X_{6}, X_{7}, X_{8}, X_{9}, X_{10}$ terhadap $Y$

\begin{tabular}{|c|c|c|c|c|c|c|}
\hline & \multirow[t]{2}{*}{ Model } & \multicolumn{2}{|c|}{ Unstandardized Coefficients } & $\begin{array}{c}\text { Standardized } \\
\text { Coefficients } \\
\end{array}$ & \multirow[t]{2}{*}{$\mathbf{t}$} & \multirow[t]{2}{*}{ Sig. } \\
\hline & & B & Std. Error & Beta & & \\
\hline \multirow[t]{11}{*}{1} & (Constant) & 3.579 & 1.398 & & 2.559 & .125 \\
\hline & X.1 & .334 & .325 & .310 & 1.028 & .412 \\
\hline & X.2 & .026 & .423 & .027 & .061 & .957 \\
\hline & X.3 & -.503 & .405 & -.781 & -1.242 & .340 \\
\hline & X.4 & .754 & .708 & .850 & 1.066 & .398 \\
\hline & X.5 & -.324 & .433 & -.687 & -.748 & .532 \\
\hline & X.6 & .076 & .544 & .077 & .140 & .901 \\
\hline & X.7 & -.123 & .374 & -.213 & -.329 & .773 \\
\hline & X.8 & -.327 & .523 & -.546 & -.625 & .596 \\
\hline & X.9 & .395 & .415 & .635 & .950 & .442 \\
\hline & X.10 & -.219 & .485 & -.282 & -.453 & .695 \\
\hline
\end{tabular}

a. Dependent Variable: $\mathrm{Y}$

Sumber: data primer diolah.

\section{Analisis Kuantitatif}

\section{Regresi Linear Berganda}

Pengujian hipotesis dalam penelitian ini dilakukan dengan menggunakan Model Regresi Linear Berganda yang merupakan metode statistika yang dipakai untuk mengetahui pola hubungan antar variabel. Model regresi ini terdiri lebih dari satu variabel independen. Analisis Regresi Linear Berganda digunakan untuk mengetahui hubungan dan pengaruh variabel independen $(\mathrm{X})$ terhadap variabel dependen $(\mathrm{Y})$. Dari perhitungan dengan menggunakan program SPSS 16 diperoleh hasil dalam Tabel 12. Hasil analisis menunjukkan nilai konstanta besarnya 3,579 menunjukan besarnya 
kinerja karyawan pada saat variabel-variabel independen nol adalah sebesar 3,579. Dari tabel di atas, maka dapat disimpulkan persamaan regresi sebagai berikut:

$$
\begin{aligned}
Y= & 3,579+0,0,334 X_{1}+0,026 X_{2}-0,503 X_{3}+0,754 X_{4}-0,324 X_{5}+0,076 X_{6}- \\
& 0,123 X_{7}-0,327 X_{8}+0,395 X_{9}-0,219 X_{10}+e_{i}
\end{aligned}
$$

\section{Pengujian Hipotesis}

Uji t

Uji $\mathrm{t}$ merupakan pengujian variabel-variabel independen individu untuk mengetahui apakah variabel independen secara individu berpengaruh secara signifikan terhadap variabel dependen.

a. Uji t variabel $\mathrm{X}_{1}, \mathrm{X}_{2}, \mathrm{X}_{3}, \mathrm{X}_{4}, \mathrm{X}_{5}, \mathrm{X}_{6}, \mathrm{X}_{7}, \mathrm{X}_{8}, \mathrm{X}_{9}, \mathrm{X}_{10}$ terhadap $\mathrm{Y}$

Tabel berikut menjelaskan hasil uji t pada variabel $\mathrm{X}_{1}$ sampai dengan $\mathrm{X}_{10}$ terhadap variabel Y:

\begin{tabular}{|c|c|c|c|c|c|}
\hline \multirow[t]{2}{*}{ Model } & \multicolumn{2}{|c|}{ Unstandardized Coefficients } & $\begin{array}{c}\text { Standardized } \\
\text { Coefficients }\end{array}$ & \multirow[t]{2}{*}{$\mathbf{t}$} & \multirow[t]{2}{*}{ Sig. } \\
\hline & B & Std. Error & Beta & & \\
\hline $1 \quad$ (Constant) & 3.579 & 1.398 & & 2.559 & .125 \\
\hline X.1 & .334 & .325 & .310 & 1.028 & .412 \\
\hline X.2 & .026 & .423 & .027 & .061 & .957 \\
\hline X.3 & -.503 & .405 & -.781 & -1.242 & .340 \\
\hline X.4 & .754 & .708 & .850 & 1.066 & .398 \\
\hline X.5 & -.324 & .433 & -.687 & -.748 & .532 \\
\hline X.6 & .076 & .544 & .077 & .140 & .901 \\
\hline X.7 & -.123 & .374 & -.213 & -.329 & .773 \\
\hline X.8 & -.327 & .523 & -.546 & -.625 & .596 \\
\hline X.9 & .395 & .415 & .635 & .950 & .442 \\
\hline X.10 & -.219 & .485 & -.282 & -.453 & .695 \\
\hline
\end{tabular}

Tabel 13. Uji t variabel $X_{1}, X_{2}, X_{3}, X_{4}, X_{5}, X_{6}, X_{7}, X_{8}, X_{9}, X_{10}$ terhadap $Y$

a. Dependent Variable: Y

Sumber: Data primer yang telah diolah.

Dari tabel di atas dapat dijelas sebagai berikut:

Perumusan Hipotesis:

$\mathrm{H}_{0}: \beta \mathrm{i}=0$ tidak ada pengaruh yang signifikan dari $\mathrm{Xi}$ terhadap $\mathrm{Y}$

$\mathrm{H}_{\mathrm{a}}: \beta \mathrm{i} \neq 0$ ada pengaruh yang signifikan dari Xi terhadap $\mathrm{Y}(\mathrm{i}=1,2, \ldots, 10)$.

$\mathrm{t}_{\text {tabel }}=\mathrm{t}_{\alpha / 2, \mathrm{~d} . \mathrm{f}}=\mathrm{t}_{0,025,3}=4,30$

Karena semua nilai $t_{\text {hit }}<t_{\text {tabel }}$ atau semua nilai probabilitas $>0,05$ maka semua $\mathrm{H}_{0}$ diterima. Jadi, semua variabel employee engagement yang terdiri atas variabel connect $\left(\mathrm{X}_{1}\right)$, career $\left(\mathrm{X}_{2}\right)$, clarity $\left(\mathrm{X}_{3}\right)$, convey $\left(\mathrm{X}_{4}\right)$, congratulate $\left(\mathrm{X}_{5}\right)$, contribute $\left(\mathrm{X}_{6}\right)$, control $\left(\mathrm{X}_{7}\right)$, collaborate $\left(\mathrm{X}_{8}\right)$, credibility $\left(\mathrm{X}_{9}\right)$, dan confidence $\left(\mathrm{X}_{10}\right)$ tidak berpengaruh secara signifikan terhadap kinerja karyawan $(\mathrm{Y})$.

Berdasarkan hasil analisis, tidak terdapat variabel yang mempengaruhi kinerja karyawan. Namun, jika dilihat dari nilai koefisien, maka terlihat variabel convey memiliki pengaruh yang paling besar dengan koefisien regrasi 0,754 yang berarti ketika convey mengalami kenaikan sebesar $1 \%$, maka kinerja karyawan naik sebesar $0,754 \%$. 


\section{Uji F}

Hasil uji $\mathrm{F}$ pengaruh variabel $\mathrm{X}_{1}, \mathrm{X}_{2}, \mathrm{X}_{3}, \mathrm{X}_{4}, \mathrm{X}_{5}, \mathrm{X}_{6}, \mathrm{X}_{7}, \mathrm{X}_{8}, \mathrm{X}_{9}, \mathrm{X}_{10}$ secara bersamasama (serempak) terhadap variabel $\mathrm{Y}$ sebagai berukut:

Perumusan Hipotesis

$\mathrm{H}_{0}: \beta 1=\beta 2=\ldots=\beta 10=0$. Variabel $\mathrm{Xi}$ secara serempak tidak berpengaruh signifikan terhadap variabel $\mathrm{Y}$.

$\mathrm{H}_{\mathrm{a}}$ : paling tidak terdapat satu $\beta$ tidak sama dengan nol. Variabel Xi secara bersamasama berpengaruh signifikan terhadap variabel $Y$

$\mathrm{F}_{\text {tabel }}$ dengan df numerator $(\mathrm{k}-1)=9$ dan df denominator $(\mathrm{n}-\mathrm{k})=3$ adalah $\mathrm{F}_{\text {tabel }}=8,81$.

Tabel 14. Uji F Variabel $X_{1}, X_{2}, X_{3}, X_{4}, X_{5}, X_{6}, X_{7}, X_{8}, X_{9}, X_{10}$ terhadap Variabel $Y$

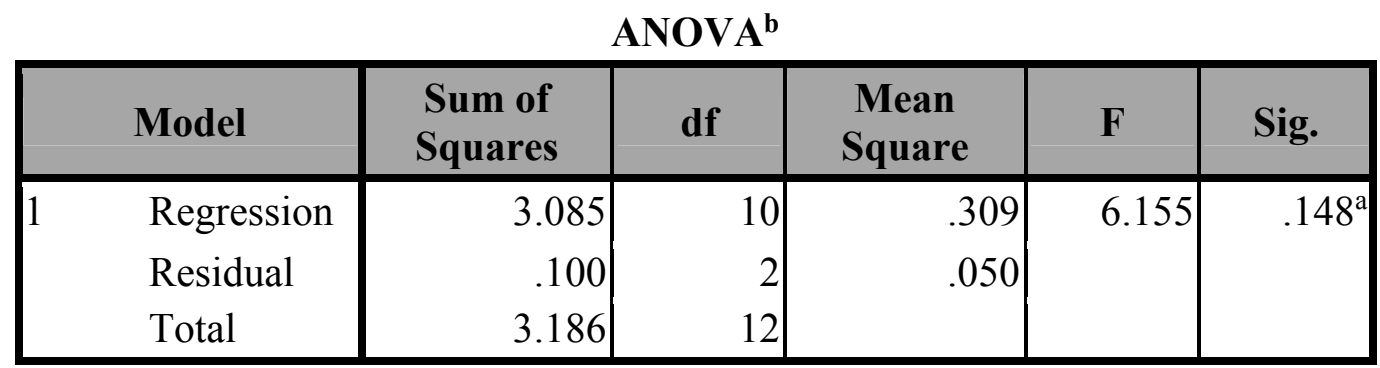

a. Predictors: (Constant), X.10, X.1, X.2, X.4, X.5, X.3, X.6, X.9,

X.7, X.8

b. Dependent Variable: Y

Sumber: Data primer yang telah diolah.

Jadi, karena $\mathrm{F}_{\text {tabel }}$ lebih besar dari $\mathrm{F}_{\text {hitung }}(8,81>6,155)$ atau probabilitas $(0,148)$ $>0,05$ maka $\mathrm{H}_{0}$ diterima, artinya variabel employee engagement (Xi) secara bersamasama tidak berpengaruh secara signifikan terhadap variabel kinerja karyawan (Y).

\section{KESIMPULAN DAN SARAN}

\section{A. Kesimpulan}

Berdasarkan hasil penelitian ini, maka dapat kesimpulan yang dapat diambil sebagai berikut:

1. Terdapat pengaruh yang positif tetapi tidak signifikan antara employee engagement terhadap kinerja karyawan Program D-3 Fakultas Ekonomi di Universitas Islam Indonesia Yogyakarta, sehingga dapat dinyatakan bahwa hipotesis pertama tidak terbukti atau ditolak.

2. Berdasarkan perhitungan yang dilakukan dengan uji $t$ tentang pengaruh employee engagement terhadap kinerja karyawan Program D-3 Fakultas Ekonomi di Universitas Islam Indonesia Yogyakarta, diperoleh hasil bahwa faktor collaborate bukan faktor yang paling dominan mempengaruhi kinerja karyawan Program D-3 Fakultas Ekonomi di Universitas Islam Indonesia Yogyakarta, sehingga dapat dinyatakan bahwa hipotesis kedua yang telah dikemukakan sebelumnya tidak terbukti atau ditolak. 


\section{B. Saran}

Dalam lingkungan persaingan antarinstitusi pendidikan saat ini yang cepat berubah dan sarat dengan ketidakpastian, maka untuk mempertahankan kinerja karyawannya, Program D-3 Fakultas Ekonomi di Universitas Islam Indonesia Yogyakarta perlu melakukan hal-hal sebagai berikut:

1. Pada variabel employee engagement yang belum memberikan pengaruh terhadap kinerja karyawan Program D-3 Fakultas Ekonomi Universitas Islam Indonesia Yogyakarta harus senantiasa mengupayakan program-program pelatihan teknis yang terkait dengan komunikasi dan kolaborasi antara pemimpin dengan karyawan serta aktivitas-aktivitas yang bersifat outbound training, sharing session, atau family gathering sebagai salah satu upaya membangun keterikatan karyawan terhadap organisasi.

2. Salah satu upaya meningkatkan dan mempertahankan faktor convey pada variabel employee engagement yang dimiliki karyawan, maka manajemen Program D-3 Fakultas Ekonomi Universitas Islam Indonesia Yogyakarta diharapkan dapat senantiasa memberikan umpan balik yang aplikatif melalui program pelatihan pengembangan diri karyawan, pelatihan koordinasi antarkaryawan, pelatihan pengembangan ketrampilan atau keahlian khusus karyawan, dan senantiasa memberikan kesempatan, dukungan, dan apresiasi yang lebih kepada karyawan yang memiliki ide-ide kreatif untuk mengekspresikannya, sehingga kinerja organisasi secara keseluruhan dapat ditingkatkan.

\section{DAFTAR REFERENSI}

Alwi, S. (2008). Manajemen Sumber Daya Manusia: Strategi Keunggulan Kompetitif. Edisi Kedua. Yogyakarta: BPFE.

Bernardin, H.J. (2010). Human Resource Management: An Experiential Approach. Fifth Edition. Singapore: McGraw-Hill Book, Inc.

Crim, D. \& Seijts, G.H. (2006). The 10 Cs of Employee Engagement. Ivey Business Journal.

Cooper, D.R. \& Schindler, P.S. (2008). Business Research Method. Tenth Edition. New York: The McGraw-Hill, Inc.

Gallup. (2013). State of The Global Workplace: Employee Engagement Insights for Business Leaders Worldwide. Gallup, Inc.

Heskett, J., Jones, T.O., Loveman, G.W., Sasser Jr., W.E, \& Schlesinger, L.A. (1994). Putting The Service-Profit Chain To Work. Harvard Business Review.

Indriantoro, N. \& Soepomo, B. (1999). Metodologi Penelitian Bisnis. Edisi Pertama. Yogyakarta: BPFE.

Kular, G., Rees, S., \& Truss, K. (2008). Employee Engagement: A Literature Review. Kingston Business School Working Paper Series, No.19. in Nunnally, J. (1967). Psychometric Methods. New York: McGraw-Hill, Inc.

Saks, A.M. \& Gruman, J.A. (2014). What Do We Really Know About Employee Engagement? Human Resources Development Quarterly, Vol 25, No.2.

Sekaran, U. (2000). Research Methods for Business. Jakarta: Gramedia Pustaka Utama. 
Simamora, H. (2004). Manajemen Sumber Daya Manusia. Edisi Ketiga. Yogyakarta: BP STIE YKPN.

Sugiyono. (2006). Metode Penelitian Kuantitatif Kualitatif dan R\&D. Bandung: Alfabeta.

Suparyadi. (.....). Manajemen Sumber Daya Manusia: Menciptakan Keunggulan Bersaing Berbasis Kompetensi SDM. Yogyakarta: Andi Offset.

Widarjono, A. (2009). Ekonometrika Pengantar dan Aplikasinya. Edisi Ketiga. Yogyakarta: Ekonisia. 